\title{
Suicidality in Major Depressive Disorder in a Nigerian Psychiatric Hospital-Is There Any Relationship?
}

\section{Sunday Onyemaechi Oriji ${ }^{*}$, Bawo Onesirosan James², Paul Ojieiriaikhi Erohubie ${ }^{3}$, Justus Uchenna Onu${ }^{1}$, Theclar Ogochukwu Iyidobi ${ }^{4}$, Obumneme Kenechukwu Nwiyi ${ }^{1}$, Chijioke Chimbo5, Richard Uwakwe ${ }^{1}$}

\author{
${ }^{1}$ Department of Mental Health, Nnamdi Azikiwe University, Awka, Anambra State, Nigeria \\ ${ }^{2}$ Federal Neuro-Psychiatric Hospital, Benin City, Nigeria \\ ${ }^{3}$ Department of Mental Health, Irrua Specialist Teaching Hospital, Irrua, Edo State, Nigeria \\ ${ }^{4}$ Department of Psychological Medicine, University of Nigeria Nsukka, Enugu Campus, Nigeria \\ ${ }^{5}$ Health Management Board, Jalingo, Taraba State, Nigeria \\ Email: *orijisunday@gmail.com, *so.oriji@unizik.edu.ng, bawojames@yahoo.com, erohubiepaul@gmail.com, \\ toezigbo@yahoo.com,obnoknok@yahoo.com,chimbochijioke@yahoo.com,r.uwakwe@unizik.edu.ng
}

How to cite this paper: Oriji, S. O., James, B. O., Erohubie, P. O., Onu, J. U., Iyidobi, T. O., Nwiyi, O. K., Chimbo, C., \& Uwakwe, R. (2021). Suicidality in Major Depressive Disorder in a Nigerian Psychiatric Hospital-Is There Any Relationship? Open Journal of Depression, 10, 90-102. https://doi.org/10.4236/ojd.2021.102006

Received: March 12, 2021

Accepted: May 15, 2021

Published: May 18, 2021

Copyright $\odot 2021$ by author(s) and Scientific Research Publishing Inc. This work is licensed under the Creative Commons Attribution International License (CC BY 4.0).

http://creativecommons.org/licenses/by/4.0/

\begin{abstract}
Background: There is increasing resurgence of suicide globally, especially in developing countries, probably owing to socio-economic instability. Majority of suicidal phenomenon is attributed to depressive disorders, which significantly contribute to the global burden of diseases. Aim: This study assessed the prevalence and correlates of suicidality (suicidal ideation and attempts) among adult outpatients with major depression at Federal Neuro-Psychiatric Hospital (FNPH), Benin City, Nigeria. Method: A cross-sectional study conducted between March and June 2018 utilizing systematic random sampling of eligible participants, aged between 18 and 64 years. One hundred and thirty-two patients with major depression, with their diagnosis confirmed with the Depression module of the Mini International Neuropsychiatric Interview (MINI) were recruited. A Socio-Demographic Questionnaire, the Brief Psychiatric Rating Scale (BPRS), the Pittsburgh Sleep Quality Index (PSQI) and Suicidality Module of MINI were administered to consented participants. Results: The past month prevalence of suicidality and suicidal ideation were $47.7 \%$ (n $=63)$ and $36.4 \%(\mathrm{n}=48)$ respectively. While, the lifetime prevalence of suicidal attempts was $18.2 \%(\mathrm{n}=24)$, the current suicidal 'moderate-high risk' was $12.1 \%(\mathrm{n}=16)$. Participants were $35 \%$ more likely to report suicidality for every unit increase in symptom severity (BPRS score) (aOR 1.35; 95\% CI $1.20-1.52, \mathrm{P}=0.001$ ). Conclusion: Suicidality is common among outpatients with major depression at the Federal Neuro-Psychiatric Hospital, Benin City.
\end{abstract}


Severity of psychopathology was an independent risk factor for suicidality in depressive disorder.

\section{Keywords}

Suicidality, Poor Sleep Quality, Symptom Severity, Depression

\section{Introduction}

Majority of suicides are associated with an underlying mental disorder, especially major depressive disorder, hence the prompt treatment of major depression is vital in reducing the rates of suicidality. Depressive disorders account for about two-thirds of suicide and carry up to a twenty-fold increase in the lifetime risk of suicide (Gaynes et al., 2004). Suicidal ideation is defined as a desire to die, or at least an indifference towards living, that may be accompanied by specific plans to kill oneself while 'suicide attempt' is a potentially self-injurious behaviour, associated with at least some intent to die, as a result of the act (Posner et al., 2007).

Suicide completion is usually preceded by various suicidal stages. First, the individual who is experiencing overwhelming stress passes through a phase of hopelessness, followed by entertainment of suicidal ideation or thoughts, then progressing to a suicidal plan, and finally carries out an attempt that may or may not lead to death. Suicidality is a complex behaviour with numerous predisposing factors (Isometsä, 2014) especially mental disorders. Over ninety percent of suicides are committed by individuals with mental disorders, especially depression (Park et al., 2015; Gunnell \& Lewis, 2005; Shibre et al., 2014). There is a paucity of evidence regarding suicidality in Nigeria among persons with mental illness.

Depressive disorders are common psychiatric disorders with lifetime prevalence of about $19 \%$ globally (Kessler \& Bromet, 2013) and up to $49.8 \%$ in Nigeria (Salihu \& Udofia, 2016). It is characterized mainly by low mood, reduced or loss of interest in previously pleasurable activities and reduced energy level. Other features associated with major depression are disturbed sleep, low self-esteem, reduced attention, worthlessness, guilt feeling, hopelessness and suicidality (ICD-10, 2007). It is categorized into mild, moderate and severe depending on the number of depressive symptoms present. It is a major cause of disability and has been projected to become the second leading contributor to the global burden of disease by the year 2020 (Murray \& Lopez, 1996).

It is difficult to predict suicide (Sher, 2011), and finding significant correlates of suicidality among this high-risk population will help clinicians to promptly predict and institute mitigating management plan for the patient.

\section{Method and Materials}

\subsection{Study Design/Setting}

A cross-sectional study was carried out at the out-patient clinics of the Federal 
Neuro-Psychiatric Hospital, Benin-city, Nigeria. It is one of eight stand-alone psychiatric hospitals in Nigeria. It has a combined bed capacity of 230 beds and is a walk-in and referral centre for persons with mental health care needs around the five neighbouring states in the south-south geopolitical zone (Federal NeuroPsychiatric Hospital, Benin City, n.d.). The Out-Patient Clinics runs from Monday to Friday except on public holidays between the hours of 9 am and $3 \mathrm{pm}$ (Federal Neuro-Psychiatric Hospital, Benin City, n.d.).

\subsection{Procedure}

A total of one hundred and thirty-two patients aged between 18 and 64 years, who have a diagnosis of major depression according to the ICD-10 and confirmed with M.I.N.I-5, and who gave a written informed consent were recruited into the study. The exclusion criteria were patients that were uncooperatively agitated and or could not understand the nature of study. A systematic random sampling method was used. The first participant for each clinic day was selected by simple random sampling via balloting technique. Subsequent participants for each day were selected according to a calculated fixed interval which was four. So following the first participant, every subsequent $4^{\text {th }}$ participant was recruited into the study.

\subsection{Instruments}

1) The Psychosis module of M.I.N.I 5.0.0 English version, used to confirm diagnosis of schizophrenia. Those who were not diagnosed by the MINI were excluded from the study.

2) Socio-demographic and clinical characteristics questionnaire, that was used to obtain information such as age, gender, religion, ethnicity, marital status, educational level, employment status, occupation, duration of illness, physical illness co-morbidity, and substance abuse.

3) Pittsburgh Sleep Quality Index (PSQI), which measures subjective sleep quality over the previous month according to seven subscale domains: sleep quality, sleep latency, sleep duration, habitual sleep efficiency, sleep disturbance, use of sleeping medication, and daytime dysfunction. The range of subscale scores is $0-3$ and the sum of all seven domains yields a global score of subjective sleep quality (range $0-21$ ). A score greater than five or equal to $(\geq 5)$ represents poor subjective sleep quality with a diagnostic sensitivity of $89.6 \%$ and specificity of 86.5\% (kappa $=0.75, p<0.001$ ) (Buysse et al., 1989).

4) Suicidality module of MINI, used to assess the suicidal behaviour of the patients. There are nine questions in this module labelled $\mathrm{C} 1$ to C6. Questions $\mathrm{C} 1$ to $\mathrm{C} 5$ assessed events in the past one month while question $\mathrm{C} 6$ assesses for suicide attempt in a patient's lifetime. The module also assesses suicidal behaviour which includes suicidal intent, plan and attempt. Scores are graded as low, medium and high.

5) Brief Psychiatric Rating Scale (BPRS) (Overall \& Gorham, 1962) is a clini- 
cian rating scale used to assess presence and severity of psychopathology. It contains 18 ordered categories of symptoms of mental illnesses. A 7-point rating scale is used ranging from "not present" $=1$, to "extremely severe" $=7$.

\subsection{Ethical Consideration}

The Ethics and Research Committee of the Federal Neuro-Psychiatric Hospital, Benin City gave approval for this study on $7^{\text {th }}$ December, 2016 with reference number: PH/A.864/vol.vii/11. The nature and purpose of the study was explained to each participant and a written informed consent obtained from those who participated. All data were treated with confidentiality and anonymity was maintained. No incentive was offered for enrolment into the study.

\subsection{Statistical Analyses}

The collected data was analysed using the Statistical Package for Social Sciences (SPSS) version 23. Comparison of categorical variables with outcome variable was performed using the Chi-squared test. The continuous variables were tested for normality of data using the one-sample Kolmogorov-Smirnov test and were all found to be non-normally distributed, hence were compared with the outcome variable (suicidality) using Mann-Whitney $U$ test. The sleep quality was classified as poor (PSQI score $\geq 5$ ) and good (PSQI score $<5$ ).

Significant associations with suicidality on bivariate analysis were entered into a binary logistic regression model using suicidality as the dependent variable to ascertain independent correlates (poor sleep quality, BPRS) of suicidality. All comparisons were two-tailed and level of statistical significance was set at $p<$ 0.05 .

\section{Results}

Socio-demographic characteristics of the participants are presented in Table 1. Ninety-five $(72.0 \%)$ were female. The male to female ratio was 1 to 3 . The aver-

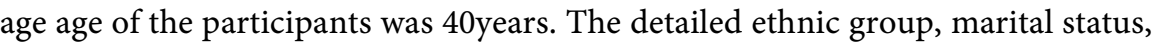
educational and employment statuses are shown in Table 1.

Regarding clinical characteristics of the participants (Table 2), about half had been diagnosed with major depression for at least forty months preceding the onset of study. Twenty-five percent of the participants have physical co-morbidity. At least, one in five had used psychoactive substance in the last one year.

Greater symptom severity was significantly associated with reporting suicidality (see Table 3 and Table 4). No other socio-demographic/clinical variables studied, had a statistically significant association with suicidality (see Table 3 and Table 4).

Forty-seven percent of the participants $(n=62 ; 47 \%)$ reported poor subjective sleep quality. Those who reported poor sleep quality were at least twice more likely to report suicidality when compared to those with good sleep quality (see Table 5). Results of binary logistic regression analysis predicting suicidality is 
presented in Table 6. Participants with a unit increase in symptom severity (BPRS score) were $35 \%$ more likely to report suicidality.

Table 1. Socio-demographic characteristics of participants.

\begin{tabular}{ccc}
\hline Variable & Category & Depression \\
\hline \multirow{2}{*}{ Age (years) } & $18-31$ & \\
& $32-38$ & Mean SD \\
& $39-46$ & 40.5510 .89 \\
& $47-64$ & \\
\hline Gender & Male & $37(28.0)$ \\
& Female & $95(72.0)$ \\
Religion & Christian & $130(98.5)$ \\
& Muslim & $2(1.5)$ \\
\hline Ethnic group & Bini/Edo & $86(65.2)$ \\
& Others & $46(34.8)$ \\
\hline Marital Status & Married & $72(54.5)$ \\
& Single & $60(45.5)$ \\
\hline Income/ & No formal education & $5(3.8)$ \\
Educational status & Primary/Secondary & $83(62.9)$ \\
& Tertiary & $44(33.3)$ \\
\hline Employment status & Unemployed & $32(24.3)$ \\
& Employed & $67(50.8)$ \\
\hline & >50 & $65(49.2)$ \\
\hline
\end{tabular}

Table 2. Clinical characteristics of participants.

\begin{tabular}{|c|c|c|}
\hline Variable & Category & Depression \\
\hline \multirow{4}{*}{ Duration of mental illness (months) } & $1-18$ & \\
\hline & $19-36$ & Mean SD \\
\hline & $37-96$ & 40.1646 .12 \\
\hline & $97-396$ & \\
\hline \multirow{2}{*}{ Have a physical co-morbidity } & Yes & $33(25.0)$ \\
\hline & No & $99(75.0)$ \\
\hline \multirow{2}{*}{ Substance use in past year } & Yes & $36(27.3)$ \\
\hline & No & $96(72.7)$ \\
\hline \multirow{2}{*}{ Substance use in lifetime } & Yes & $68(51.5)$ \\
\hline & No & $64(48.5)$ \\
\hline \multirow{5}{*}{$\begin{array}{l}\text { Lifetime substance use pattern } \\
\qquad(\mathrm{n}=59)\end{array}$} & Alcohol & $59(86.8)$ \\
\hline & Tobacco & $6(8.8)$ \\
\hline & Alcohol + Tobacco & $1(1.5)$ \\
\hline & Tobacco + Cannabis & $1(1.5)$ \\
\hline & Alcohol + Tobacco + Cannabis & $1(1.5)$ \\
\hline
\end{tabular}


Table 3. Comparison of presence/absence of suicidality and socio-demographics.

\begin{tabular}{cccccc}
\hline \multirow{2}{*}{ Variable } & Category & \multicolumn{2}{c}{ Suicidality } & \multirow{2}{*}{$\chi^{2}$} & $\mathcal{P}$ \\
\cline { 3 - 4 } Gender & Male & Present & Absent & & \\
\hline \multirow{2}{*}{ Marital status } & Female & $18(48.6)$ & $19(51.4)$ & 0.02 & 0.90 \\
& Single & $29(47.4)$ & $50(52.6)$ & & \\
\hline \multirow{2}{*}{ Education } & Married & $34(47.2)$ & $38(52.8)$ & 0.02 & 0.90 \\
& No formal education & $4(80.0)$ & $1(20.0)$ & & \\
\hline \multirow{2}{*}{ Employment } & Primary and secondary & $42(50.6)$ & $41(49.4)$ & 3.82 & $0.15^{\sharp}$ \\
& Tertiary & $17(38.6)$ & $27(61.4)$ & & \\
\hline Have physical & Unemployed & $13(40.6)$ & $19(59.4)$ & 0.85 & 0.36 \\
comorbidity & Employed & $50(50.0)$ & $50(50.0)$ & & \\
\hline Past year & Yes & $15(45.5)$ & $18(54.5)$ & 0.09 & 0.76 \\
substance use & No & $48(48.5)$ & $51(51.5)$ & & \\
\hline Lifetime & Yes & $19(52.8)$ & $17(47.2)$ & 0.51 & 0.48 \\
substance use & No & $44(45.8)$ & $52(54.2)$ & & \\
\hline
\end{tabular}

${ }^{\#}$ Yates corrected $\chi^{2}$.

Table 4. Comparison of selected socio-demographic and clinical variables (continuous data) with presence/absence of suicidality.

\begin{tabular}{cccccc}
\hline \multirow{2}{*}{ Variable } & \multicolumn{2}{c}{ Suicidality* } & \multirow{2}{*}{ MWU $^{*}$} & $\boldsymbol{p}$ \\
\cline { 2 - 3 } & Present & Absent & & \\
\hline Age & 38.5 & 42 & 1972.0 & 0.36 \\
Monthly income/allowance (US) & 42 & 42 & 2139.5 & 0.88 \\
Duration of illness (months) & 24 & 24 & 1919.5 & 0.25 \\
BPRS & 25 & 19 & 758.0 & $\mathbf{0 . 0 0 1}$ \\
\hline
\end{tabular}

*Median score. ${ }^{*}$ Mann-Whitney U.

Table 5. Comparison of presence of suicidality and poor sleep quality.

\begin{tabular}{lcccccc}
\hline & \multicolumn{2}{c}{ Suicidality } & & \multirow{2}{*}{$\chi^{2}$} & $\boldsymbol{P}$ & OR (95\%CI) \\
\cline { 2 - 3 } & Present & Absent & & & \\
\hline Poor sleep quality & $41(58.6)$ & $29(41.4)$ & 7.03 & $\mathbf{0 . 0 1}$ & $2.57(1.20-5.53)$ \\
Good sleep quality & $22(35.5)$ & $40(64.5)$ & & & \\
\hline
\end{tabular}

Table 6. Independent Correlates of Suicidality.

\begin{tabular}{cccccc}
\hline Variable & B & SE & Wald & OR (95\% CI) & $P$ \\
\hline Constant & -6.849 & 1.273 & 28.944 & & \\
Poor sleep quality & 0.009 & 0.441 & 0.000 & $1.01(0.43-2.39)$ & 0.98 \\
BPRS & 0.300 & 0.059 & 25.515 & $1.35(1.20-1.52)$ & $\mathbf{0 . 0 0 1}$ \\
\hline
\end{tabular}

Keys: B = Regression Coefficient; $\mathrm{SE}=$ Standard Error of Regression Coefficient; Wald = Wald Chi-square. 


\section{Discussion}

\subsection{Prevalence of Current Suicidal Ideation and Lifetime Suicidal Attempt}

A past-month prevalence of $36.4 \%$ of suicidal ideation among participants with major depression was found in this study. And this is in keeping with what have been reported in an earlier study by Vuorilehto et al. in Finland, where suicidal ideation in a particular group of patients with major depression were assessed by different instruments and a prevalence rate ranging between $8.0 \%$ to $44 \%$ (Vuorilehto et al., 2014) was reported. This implies that variation in prevalence of suicidality among patients could depend partly on the type of assessment tool employed.

However, the finding in this study is slightly higher than that reported by Khan (Khan et al., 2012) in Malaysia. It was a retrospective study; hence there could be a reporting bias. Furthermore, the authors reported that the majority of the case files showed that patients' suicidal behaviour were not assessed by a validated instrument, hence some suicidal data might have been missed. A far lower current prevalence of suicidal ideation of $18.9 \%$ compared to what is obtained in this study (36.4\%) has been reported by DeVylder et al. in the United State (DeVylder et al., 2015). The difference in the prevalence rates between this study and that of DeVylder et al. could be attributed to the fact that the former focused only on the patients with major depression while the latter involved individual with any mental disorder. Also, while this study is a hospital-based study, DeVylder study was community-based. A cross-sectional study in Singapore reported suicidal ideation prevalence rate of $43.6 \%$ among those with major depressive disorder (Subramaniam et al., 2014). This rate is much higher than that obtained in the present study probably because of the longer duration of twelve months considered in assessing the participants suicidality unlike this study that evaluated suicidal ideation in the last one month according to suicidality module of MINI.

This study revealed an $18.2 \%$ lifetime prevalence of suicidal attempt among participants with major depression. This implies that at least one in five of those with depression have had a suicidal attempt in his or her lifetime. This is in contrast to what was reported by Banwari et al. (Banwari et al., 2013) which states that nearly one in two (44.0\%) had a lifetime suicidal attempt. The very small sample of fifty participants used by Banwari et al. could explain the disparity as this would have reduced the statistical power of the study. Also, the lifetime prevalence of suicidal attempts among the participants with depression in this study is slightly higher than prevalence values reported by Khan et al. (15.2\%) (Khan et al., 2012) and Vuorilehto et al. (17.0\%) (Vuorilehto et al., 2006). The inconsistency of previous findings with this study may be as a result of methodological differences. For example, Khan et al.'s study (Khan et al., 2012) was a retrospective study design, and Vuorilehto et al. (Vuorilehto et al., 2006) reported that they assessed suicidal attempt without a validated or standardized 
instrument, unlike in this study. Despite the location differences, the finding of this study has a near comparability with the rates found in Japan (20.0\%) (Ishii et al., 2014) and Netherlands (20.4\%) (Stringer et al., 2013) and in United Kingdom (20.5\%) (Heslin et al., 2016).

\subsection{Correlates of Suicidality}

Poor subjective sleep quality had no independent association with suicidality in this study. This finding is contrary to existing literatures documenting significant association of poor sleep quality with increased odds of suicidal behaviours among individuals with major depressive disorder (Bernert et al., 2014). Gelaye et al. (Gelaye et al., 2015) study population comprised only female gender unlike in this study that recruited both male and female populations. Earlier studies has reported female preponderance in having depression (Akechi et al., 2010; Schuch et al., 2014), and experiencing more sleep problem compared to males (Guo et al., 2014). Bernert et al. (Bernert et al., 2014) in their follow-up study focused on community-based old age population, and not on patients with major depression.

Also, a significant finding in this study is the independent impact of severity of depressive symptomatology on suicidality. Every unit increase in depression symptom severity as measured by Brief Psychiatric Rating Scale (BPRS) is accompanied by $29 \%$ increased odds of suicidality in this study. Arnold et al. (Arnold et al., 2013) in their multivariate analysis observed similar significant association between depression symptom severity score and suicidal behaviour. Some other studies also reported significant association between severity of depression and major depression (Hawton et al., 2013; Vuorilehto et al., 2006).

The finding in this study is in keeping with some research evidences (Chan et al., 2011; Lim et al., 2014) which shows that there is no significant association between age and suicidality among individuals with depression. However, Wang et al. reported that depressed patients older than 45 years were more likely to be suicidal compared to those younger than 45 years (Wang et al., 2015). The likely explanation for such difference could be due to the fact that this study evaluated participants within the age range of 18 and 64 years, unlike the latter that included individuals with age more than 64 years.

Similarly, the association between gender and suicidality did not attain statistical significance. However, the trend shows that males with depression are more likely to be suicidal than their female counterparts as observed in some other studies as well (Moreno-Küstner et al., 2016; Srivastava \& Kumar, 2005). The fact that males having depression experience greater social stigma (Hawton, 2000), more financial, health and occupational problems could be a predisposition to higher suicidal behaviour (Kawashima et al., 2012; Narishige et al., 2014). More so, males indulge more in substance use which increases their susceptibility to suicidality, especially due to impulsivity and impaired cognition associated with substance abuse (Lamis \& Malone, 2012). A further explanation of the associa- 
tion between gender and suicidality among individuals with depression might be related to the difference in severity of depression between the sexes. Ryan et al. (Ryan et al., 2008) found that, compared with women, men had less depression but, if depressed, they were more severely depressed than women.

The relationship between educational status and suicidality in individuals with major depression has been inconsistent in several research reports. For instance, Gan et al. (Gan et al., 2012) observed significant relationship between high educational achievement and suicidality, which is contrary to the findings of this study. The inconsistency may be due to methodological differences, for instance, while this study assessed both genders of wider age range of 18 and 64 years, Gan et al. recruited only females between the ages of 30 to 60 years. Some other studies (Choi et al., 2017; Ruengorn et al., 2012; Subramaniam et al., 2014) including this study, did not show significant association between educational attainment and suicidal behaviour.

Unemployment is linked to socioeconomic problems, and financial poverty is a known risk factor for suicidality (Córdoba-Doña et al., 2014), however, this study found no association between unemployment and suicidality. Ruengorn et al. (Ruengorn et al., 2012) reported similar finding but Koponen et al. (Koponen et al., 2015) reported the contrary. Factors such as marital status (Inder et al., 2014), physical comorbidity (Duggan et al., 1991), substance use (Isometsä, 2014; Riihimäki et al., 2014; Wang et al., 2015) and duration of illness (Schaub et al., 2013) have been associated with suicidality in previous study but not in this study. The inconsistency of these findings may be attributed to discrepancies in the population studied and methodology differences.

\section{Limitations and Future Directions}

This study was conducted in a single facility, hence may require a cautious generalization of the results. Secondly, being a cross-sectional study, identifying a causal relationship between severity of psychopathology and suicidality was not possible. Further research employing multi-centre and or longitudinal design are vital to explore the causal relationship between symptom severity, and suicidality.

\section{Conclusion and Recommendation}

This study reveals that suicidality among adult out-patients with depression at the Federal Neuro-Psychiatric Hospital, Benin City is high. At least one in ten patients has moderate-high suicidal risk. Severity of psychopathology is an independent risk factor for suicidality. Awareness campaign for early presentation and intervention will help reduce the illness severity, hence minimize suicidality.

\section{Contribution Details}

Oriji, Erohubie, Chimbo and James were involved in the conceptualization and data collection and analysis. Oriji, Onu, Iyidobi, Nwiyi and Uwakwe drafted, ed- 
ited and reviewed the manuscript. All authors perused and approved the final draft for submission.

\section{Data Availability Statement}

The data that support the findings of this study are available from the corresponding author (Oriji S O) upon reasonable request.

\section{Disclaimer}

The authors own the views expressed in this submitted article; and not an official position of the institution.

\section{Conflicts of Interest}

The authors declare no conflicts of interest regarding the publication of this paper.

\section{References}

Akechi, T., Okamura, H., Nakano, T., Akizuki, N., Okamura, M., Shimizu, K., Okuyama, T., Furukawa, T. A., \& Uchitomi, Y. (2010). Gender Differences in Factors Associated with Suicidal Ideation in Major Depression among Cancer Patients. Psycho-Oncology, 19, 384-389. https://doi.org/10.1002/pon.1587

Arnold, E. M., McCall, V. W., Anderson, A., Bryant, A., \& Bell, R. (2013). Sleep Problems, Suicidality and Depression among American Indian Youth. Journal of Sleep Disor ders-Treatment \& Care, 2, 119.

Banwari, G. H., Vankar, G. K., \& Parikh, M. N. (2013). Comparison of Suicide Attempts in Schizophrenia and Major Depressive Disorder: An Exploratory Study. Asia-Pacific Psychiatry: Official Journal of the Pacific Rim College of Psychiatrists, 5, 309-315. https://doi.org/10.1111/j.1758-5872.2012.00188.x

Bernert, R. A., Turvey, C. L., Conwell, Y., \& Joiner, T. E. (2014). Association of Poor Subjective Sleep Quality with Risk for Death by Suicide during a 10-Year Period: A Longitudinal, Population-Based Study of Late Life. JAMA Psychiatry, 71, 1129-1137. https://doi.org/10.1001/jamapsychiatry.2014.1126

Buysse, D., Reynolds, C., Monk, T., Berman, S., \& Kupfer, D. J. (1989). The Pittsburgh Sleep Quality Index: A New Instrument for Psychiatric Practice and Research. Psychiatry Research, 28, 193-213. https://doi.org/10.1016/0165-1781(89)90047-4

Chan, L. F., Maniam, T., \& Shamsul, A. S. (2011). Suicide Attempts among Depressed in Patients with Depressive Disorder in a Malaysian Sample: Psychosocial and Clinical Risk Factors. Crisis, 32, 283-287. https://doi.org/10.1027/0227-5910/a000088

Choi, S. B., Lee, W., Yoon, J.-H., Won, J.-U., \& Kim, D. W. (2017). Risk Factors of Suicide Attempt among People with Suicidal Ideation in South Korea: A Cross-Sectional Study. BMC Public Health, 17, Article No. 579. https://doi.org/10.1186/s12889-017-4491-5

Córdoba-Doña, J. A., San Sebastián, M., Escolar-Pujolar, A., Martínez-Faure, J. E., \& Gustafsson, P. E. (2014). Economic Crisis and Suicidal Behaviour: The Role of Unemployment, Sex and Age in Andalusia, Southern Spain. International Journal for Equity in Health, 13, Article No. 55. https://doi.org/10.1186/1475-9276-13-55

DeVylder, J. E., Lukens, E. P., Link, B. G., \& Lieberman, J. A. (2015). Suicidal Ideation and Suicide Attempts among Adults with Psychotic Experiences: Data from the Col- 
laborative Psychiatric Epidemiology Surveys. JAMA Psychiatry, 72, 219-225.

https://doi.org/10.1001/jamapsychiatry.2014.2663

Duggan, C. F., Sham, P., Lee, A. S., \& Murray, R. M. (1991). Can Future Suicidal Behaviour in Depressed Patients Be Predicted? Journal of Affective Disorders, 22, 111-118. https://doi.org/10.1016/0165-0327(91)90044-S

Federal Neuro-Psychiatric Hospital, Benin City. (n.d.). http://www.fnphbenin.gov.ng/pages/_ctx/pgs/adult/

Gan, Z., Li, Y., Xie, D., Shao, C., Yang, F., Shen, Y., Zhang, N., Zhang, G., Tian, T., Yin, A., Chen, C., Liu, J., Tang, C., Zhang, Z., Liu, J., Sang, W., Wang, X., Liu, T., Wei, Q. et al. (2012). The Impact of Educational Status on the Clinical Features of Major Depressive Disorder among Chinese Women. Journal of Affective Disorders, 136, 988-992. https://doi.org/10.1016/j.jad.2011.06.046

Gaynes, B. N., West, S. L., Ford, C. A., Frame, P., Klein, J., Lohr, K. N., \& U.S. Preventive Services Task Force (2004). Screening for Suicide Risk in Adults: A Summary of the Evidence for the U.S. Preventive Services Task Force. Annals of Internal Medicine, 140, 822-835. https://doi.org/10.7326/0003-4819-140-10-200405180-00015

Gelaye, B., Barrios, Y. V., Zhong, Q.-Y., Rondon, M. B., Borba, C. P. C., Sánchez, S. E., Henderson, D. C., \& Williams, M. A. (2015). Association of Poor Subjective Sleep Quality with Suicidal Ideation among Pregnant Peruvian Women. General Hospital Psychiatry, 37, 441-447. https://doi.org/10.1016/j.genhosppsych.2015.04.014

Gunnell, D., \& Lewis, G. (2005). Studying Suicide from the Life Course Perspective: Implications for Prevention. The British Journal of Psychiatry, 187, 206-208.

Guo, L., Deng, J., He, Y., Deng, X., Huang, J., Huang, G., Gao, X., \& Lu, C. (2014). Prevalence and Correlates of Sleep Disturbance and Depressive Symptoms among Chinese Adolescents: A Cross-Sectional Survey Study. BMJ Open, 4, e005517. https://doi.org/10.1136/bmjopen-2014-005517

Hawton, K. (2000). Sex and Suicide: Gender Differences in Suicidal Behaviour. The British Journal of Psychiatry, 177, 484-485. https://doi.org/10.1192/bjp.177.6.484

Hawton, K., Casañas i Comabella, C., Haw, C., \& Saunders, K. (2013). Risk Factors for Suicide in Individuals with Depression: A Systematic Review. Journal of Affective Disorders, 147, 17-28. https://doi.org/10.1016/j.jad.2013.01.004

Heslin, M., Lappin, J. M., Donoghue, K., Lomas, B., Reininghaus, U., Onyejiaka, A., Croudace, T., Jones, P. B., Murray, R. M., Fearon, P., Doody, G. A., Dazzan, P., Craig, T. J., \& Morgan, C. (2016). Ten-Year Outcomes in First Episode Psychotic Major Depression Patients Compared with Schizophrenia and Bipolar Patients. Schizophrenia Research, 176, 417-422. https://doi.org/10.1016/j.schres.2016.04.049

ICD-10. (2007). The ICD-10 Classification of Mental and Behavioural Disorders-Clinical Descriptions and Diagnostic Guidelines. Geneva: World Health Organization.

Inder, K. J., Handley, T. E., Johnston, A., Weaver, N., Coleman, C., Lewin, T. J., Slade, T., \& Kelly, B. J. (2014). Determinants of Suicidal Ideation and Suicide Attempts: Parallel Cross-Sectional Analyses Examining Geographical Location. BMC Psychiatry, 14, Article No. 208. https://doi.org/10.1186/1471-244X-14-208

Ishii, T., Hashimoto, E., Ukai, W., Kakutani, Y., Sasaki, R., \& Saito, T. (2014). Characteristics of Attempted Suicide by Patients with Schizophrenia Compared with Those with Mood Disorders: A Case-Controlled Study in Northern Japan. PLoS ONE, 9, e96272. https://doi.org/10.1371/journal.pone.0096272

Isometsä, E. (2014). Suicidal Behaviour in Mood Disorders-Who, When, and Why? The Canadian Journal of Psychiatry, 59, 120-130.

https://doi.org/10.1177/070674371405900303 
Kawashima, Y., Ito, T., Narishige, R., Saito, T., \& Okubo, Y. (2012). The Characteristics of Serious Suicide Attempters in Japanese Adolescents-Comparison Study between Adolescents and adults. BMC Psychiatry, 12, Article No. 191. https://doi.org/10.1186/1471-244X-12-191

Kessler, R. C., \& Bromet, E. J. (2013). The Epidemiology of Depression across Cultures. Annual Review of Public Health, 34, 119-138. https://doi.org/10.1146/annurev-publhealth-031912-114409

Khan, T. M., Sulaiman, S. A. S., \& Hassali, M. A. (2012). Factors Associated with Suicidal Behaviour among Depressed Patients in Penang, Malaysia. Archives of Medical Science, 8, 697-703. https://doi.org/10.5114/aoms.2012.28601

Koponen, H., Kautiainen, H., Leppänen, E., Mäntyselkä, P., \& Vanhala, M. (2015). Association between Suicidal Behaviour and Impaired Glucose Metabolism in Depressive Disorders. BMC Psychiatry, 15, Article No. 163. https://doi.org/10.1186/s12888-015-0567-x

Lamis, D. A., \& Malone, P. S. (2012). Alcohol Use and Suicidal Behaviors among Adults: A Synthesis and Theoretical Model. Suicidology Online, 3, 4-23.

Lim, A.-Y., Lee, A.-R., Hatim, A., Tian-Mei, S., Liu, C.-Y., Jeon, H., Udomratn, P., Bautista, D., Chan, E., Liu, S.-I., Chua, H., Hong, J., \& the MD RAN (2014). Clinical and Sociodemographic Correlates of Suicidality in Patients with Major Depressive Disorder from Six Asian Countries. BMC Psychiatry, 14, Article No. 37. https://doi.org/10.1186/1471-244X-14-37

Moreno-Küstner, B., Jones, R., Švab, I., Maaroos, H., Xavier, M., Geerlings, M., Torres-González, F., Nazareth, I., Motrico-Martínez, E., Montón-Franco, C., Gil-de-Gómez, M. J., Sánchez-Celaya, M., Díaz-Barreiros, M. Á., Vicens-Caldentey, C., \& King, M. (2016). Suicidality in Primary Care Patients Who Present with Sadness and Anhedonia: A Prospective European Study. BMC Psychiatry, 16, Article No. 94. https://doi.org/10.1186/s12888-016-0775-Z

Murray, C., \& Lopez, A. (1996). The Global Burden of Disease. Cambridge, MA: Harvard University Press.

Narishige, R., Kawashima, Y., Otaka, Y., Saito, T., \& Okubo, Y. (2014). Gender Differences in Suicide Attempters: A Retrospective Study of Precipitating Factors for Suicide Attempts at a Critical Emergency Unit in Japan. BMC Psychiatry, 14, Article No. 144. https://doi.org/10.1186/1471-244X-14-144

Overall, J. E., \& Gorham, D. R. (1962). The Brief Psychiatric Rating Scale. Psychological Reports, 10, 799-812. https://doi.org/10.2466/pr0.1962.10.3.799

Park, S., Choi, K. H., Oh, Y., Lee, H.-K., Kweon, Y.-S., Lee, C. T., \& Lee, K.-U. (2015). Clinical Characteristics of the Suicide Attempters Who Refused to Participate in a Suicide Prevention Case Management Program. Journal of Korean Medical Science, 30, 1490-1495. https://doi.org/10.3346/jkms.2015.30.10.1490

Posner, K., Oquendo, M. A., Gould, M., Stanley, B., \& Davies, M. (2007). Columbia Classification Algorithm of Suicide Assessment (C-CASA): Classification of Suicidal Events in the FDA's Pediatric Suicidal Risk Analysis of Antidepressants. The American Journal of Psychiatry, 164, 1035-1043. https://doi.org/10.1176/ajp.2007.164.7.1035

Riihimäki, K., Vuorilehto, M., Melartin, T., Haukka, J., \& Isometsä, E. (2014). Incidence and Predictors of Suicide Attempts among Primary-Care Patients with Depressive Disorders: A 5-Year Prospective Study. Psychological Medicine, 44, 291-302.

https://doi.org/10.1017/S0033291713000706

Ruengorn, C., Sanichwankul, K., Niwatananun, W., Mahatnirunkul, S., Pumpaisalchai, W., \& Patumanond, J. (2012). Factors Related to Suicide Attempts among Individuals 
with Major Depressive Disorder. International Journal of General Medicine, 5, 323-330. https://doi.org/10.2147/IJGM.S30874

Ryan, J., Carriere, I., Ritchie, K., Stewart, R., Toulemonde, G., Dartigues, J.-F., Tzourio, C., \& Ancelin, M.-L. (2008). Late-Life Depression and Mortality: Influence of Gender and Antidepressant Use. The British Journal of Psychiatry: The Journal of Mental Science, 192, 12-18. https://doi.org/10.1192/bjp.bp.107.039164

Salihu, A. S., \& Udofia, O. (2016). Prevalence and Associated Factors of Depression among General Outpatients in a Tertiary Institution in Kano, North-Western Nigeria. Open Journal of Psychiatry, 6, 228-236. https://doi.org/10.4236/ojpsych.2016.63028

Schaub, A., Neubauer, N., Mueser, K. T., Engel, R., \& Möller, H.-J. (2013). Neuropsychological Functioning in Inpatients with Major Depression or Schizophrenia. BMC Psychiatry, 13, Article No. 203. https://doi.org/10.1186/1471-244X-13-203

Schuch, J. J. J., Roest, A. M., Nolen, W. A., Penninx, B. W. J. H., \& de Jonge, P. (2014). Gender Differences in Major Depressive Disorder: Results from the Netherlands Study of Depression and Anxiety. Journal of Affective Disorders, 156, 156-163. https://doi.org/10.1016/j.jad.2013.12.011

Sher, L. (2011). Is It Possible to Predict Suicide? Australian and New Zealand Journal of Psychiatry, 45, 341-341. https://doi.org/10.3109/00048674.2011.560136

Shibre, T., Hanlon, C., Medhin, G., Alem, A., Kebede, D., Teferra, S., Kullgren, G., Jacobsson, L., \& Fekadu, A. (2014). Suicide and Suicide Attempts in People with Severe Mental Disorders in Butajira, Ethiopia: 10 Year Follow-Up of a Population-Based Cohort. BMC Psychiatry, 14, Article No. 150. https://doi.org/10.1186/1471-244X-14-150

Srivastava, A. S., \& Kumar, R. (2005). Suicidal Ideation and Attempts in Patients with Major Depression: Sociodemographic and Clinical Variables. Indian Journal of Psychiatry, 47, 225-228. https://doi.org/10.4103/0019-5545.43059

Stringer, B., van Meijel, B., Eikelenboom, M., Koekkoek, B., Licht, C. M. M., Kerkhof, A. J. F. M., Penninx, B. W. J. H., \& Beekman, A. T. F. (2013). Recurrent Suicide Attempts in Patients with Depressive and Anxiety Disorders: The Role of Borderline Personality Traits. Journal of Affective Disorders, 151, 23-30. https://doi.org/10.1016/j.jad.2013.02.038

Subramaniam, M., Abdin, E., Seow, E. L., Picco, L., Vaingankar, J. A., \& Chong, S. A. (2014). Suicidal Ideation, Suicidal Plan and Suicidal Attempts among Those with Major Depressive Disorder. Annals of the Academy of Medicine, Singapore, 43, 412-421.

Vuorilehto, M. S., Melartin, T. K., \& Isometsä, E. T. (2006). Suicidal Behaviour among Primary-Care Patients with Depressive Disorders. Psychological Medicine, 36, 203-210. https://doi.org/10.1017/S0033291705006550

Vuorilehto, M., Valtonen, H. M., Melartin, T., Sokero, P., Suominen, K., \& Isometsä, E. T. (2014). Method of Assessment Determines Prevalence of Suicidal Ideation among Patients with Depression. European Psychiatry, 29, 338-344.

https://doi.org/10.1016/j.eurpsy.2013.08.005

Wang, Y., Sareen, J., Afifi, T. O., Bolton, S.-L., Johnson, E. A., \& Bolton, J. M. (2015). A Population-Based Longitudinal Study of Recent Stressful Life Events as Risk Factors for Suicidal Behavior in Major Depressive Disorder. Archives of Suicide Research, 19, 202-217. https://doi.org/10.1080/13811118.2014.957448 